\title{
Analysis of static forces generated in-track on a railway sleeper resting on an elastic foundation due to structural imperfections using the PONTOS system
}

\author{
Włodzimierz Andrzej Bednarek ${ }^{1, *}$ \\ ${ }^{1}$ Poznan University of Technology, Faculty of Civil and Environmental Engineering, Piotrowo 5, 60-965 Poznań, Poland
}

\begin{abstract}
In the paper a considered railway sleeper was analysed as an Euler-Bernoulli beam and a Timoshenko beam of finite length resting on a one- and two-parameter foundation. The foundation parameters were determined based on a modified and analogue Vlasov soil model and field investigations. The main concept for the executed investigations was to induce an intentional imperfection in an actual railway track, propose a way of appropriate measurement (e.g. the PONTOS system by GOM mbh), and utilize author's field investigations results to calibrate necessary parameters for theoretical calculations. An experimental formula describing the value of the force transferred from the rail to the railway sleeper on the grounds of the survey site caused by a locomotive was given. Furthermore, the deflection of the chosen railway sleeper due to the generated imperfection was analysed. Finally the objective of the present analysis was to resolve the calculations into the beam element such that the results can be utilised in computational railway practice. In the presented paper also the computational examples, diagrams and tables reflecting influence of analyzed parameters on obtained a CWR track's displacements are enclosed.
\end{abstract}

\section{Introduction}

The problem of a beam resting on an elastic and viscoelastic foundation has been widely investigated in the literature [1-6,10-13]. The first soil model was proposed by Winkler, in which the foundation is described by a series of closely-spaced independent elastic springs. Furthermore, the reacting pressure at each point of the soil surface is directly proportional to the deflection of the beam through a material constant called the Winkler modulus [7]. However, many alternative soil models have been proposed to obtain more accurate descriptions of the soil-beam interaction and to avoid the limits of the Winkler assumption:

- a model in which the soil is modelled as a homogeneous isotropic elastic half space;

- the Wieghardt model (this model introduces a material constant $k_{\mathrm{G}}$ in addition to the typical Winkler modulus);

- the Pasternak model, which describes the foundation as an elastic spring layer covered by an elastic incompressible membrane that is shear deformable;

- the Vlasov model [14] (in this model, the foundation is treated as an elastic layer, and the constraints are imposed by restricting the deflection within the foundation to an appropriate mode shape - an arbitrary parameter $\gamma$ );

- the model with a modified Vlasov foundation, in which the parameter $\gamma$ is treated as a function of the beam and the foundation soil (using an iterative procedure).
The unilateral nature of the beam-soil contact results in a nonlinear feature. For a further analysis, in order to avoid the Winkler's assumption, the considered in this paper foundation of a sleeper is mainly treated as a twoparameter Vlasov foundation. Respectively, an analysis of static forces in a railway sleeper as an EulerBernoulli (E-B) elastic beam resting on a two-parameter modified Vlasov foundation (defined by $k_{1}[\mathrm{MPa}]$ and $k_{2}[\mathrm{MN}]$ coefficients) is done. For comparison purposes a sleeper is also modelled as an Euler-Bernoulli beam resting on an elastic one-parameter foundation (defined only by $k_{1}[\mathrm{MPa}]$ coefficient). Also an attempt is made to calculate the considered railway sleeper as a shortlength Timoshenko beam (shortly described in point 3.3) on a two-parameter analogue Vlasov foundation (suitably with $k_{\mathrm{w}}[\mathrm{MPa}]$ and $k_{\mathrm{u}}[\mathrm{MPa}]$ coefficients) for further comparison [4]. Specifically, the concentrated static forces causing the deflection of the railway sleeper are investigated.

\subsection{The concept for the executed investigations}

The main concept for the executed investigations is to induce an intentional imperfection in a railway track, propose a way of appropriate measurement, and utilize field investigations results to calibrate necessary parameters for theoretical calculations. Therefore to achieve the stated problem, the following elements are proposed and carried out:

\footnotetext{
* Corresponding author: wlodzimierz.bednarek@put.poznan.pl
} 
- a method for generation of an imperfection in a railway track,

- an analysis of force transferred from a wheel onto a sleeper caused by a generated local imperfection,

- an application of the measured values for a theoretical analysis (e.g. value of a force transferred on a railway sleeper),

- a comparison between measured and theoretical values of rail and sleeper displacements,

- an advanced method for measurement of forces and displacements.

The executed tasks are described in the paper.

As is well known the primary function of a railway sleeper is to sustain rail forces from the wheels of the rolling stock and transfer them to the ballast bed. The dimensions of a considered concrete railway sleeper are shown in fig. 1 and table 1 .

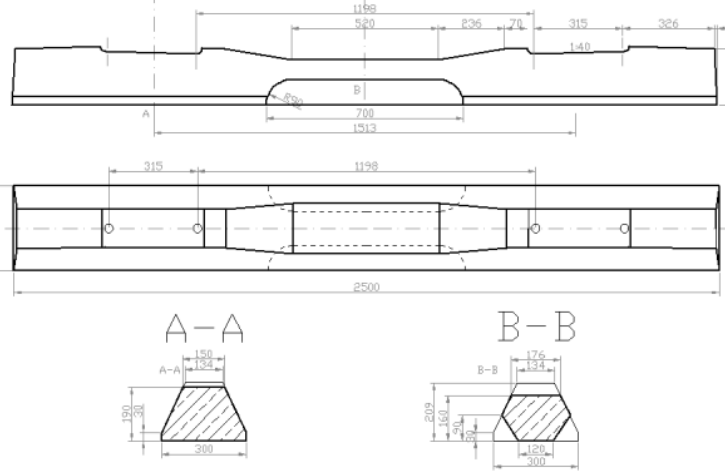

Fig. 1. Schematics of an considered in the paper INBK-7-type railway sleeper

Table 1. The dimensions of a considered concrete railway

\begin{tabular}{|c|c|c|}
\hline \multicolumn{3}{|c|}{ sleeper } \\
\hline \multicolumn{2}{|c|}{ Type } & INBK-7 \\
\hline \multicolumn{2}{|c|}{$\begin{array}{c}\text { Mass } \\
{[\mathrm{kg}]}\end{array}$} & 250 \\
\hline \multicolumn{2}{|c|}{ Support area $\left[\mathrm{m}^{2}\right]$} & 0.6310 \\
\hline \multirow{5}{*}{$\begin{array}{c}\text { Principal } \\
\text { dimensions } \\
{[\mathrm{mm}]}\end{array}$} & $\mathbf{a}$ & 315 \\
\hline & b & 1828 \\
\hline & d & 2500 \\
\hline & $\mathbf{h}$ & 190 \\
\hline & $\mathbf{p}$ & 300 \\
\hline
\end{tabular}

where: $a$ - anchor clearance; $b$ - width between external anchors; $d$-length; $h$ - height; $p$ - width of bottom area of sleeper

The following parameters are considered for the analysis of a railway sleeper as a beam resting on an elastic foundation [1]:

- the sleeper's length and width;

- the sleeper's unitary (per sleeper's length) stiffness;
- the subgrade coefficient;

- the force transferred from the rail to the railway sleeper.

For this research, various stiffness values per length of the railway sleeper are considered. The values of the subgrade coefficients for one- and two-parameter foundations and the force transferred from the rail to the railway sleeper due to the foundation type are calculated. The analysis includes the static quantities and the values of railway sleeper deflection.

\section{Theoretical backgrounds for modelling a 2D beam on elastic foundation (finite element formulation)}

Analysis of a beam on an elastic foundation by finite element method (FEM) has been published in works [4$6,8]$. Below matrices for the beam on the one- and twoparameter foundation are enclosed.

\subsection{A BE beam on a one-parameter Winkler's foundation}

The differential equation for a $\mathrm{BE}$ beam on a oneparameter soil has the following form (neglecting the beam's deadweight) [5]:

$$
\text { with } \lambda=\sqrt[4]{\frac{k_{1}}{4 \cdot E I}} \text { and } k_{1}=4 \cdot \lambda^{4} \cdot E I
$$

Neglecting the procedure of derivation the formulas, the solution of this equation in matrix form is given by [5] and fig. 2:

$$
S_{i j}=\left[\begin{array}{llll}
S_{11} & S_{22} & S_{3} & S_{14}^{-} \\
S_{21} & S_{22} & S_{23} & S_{24} \\
S_{31} & S_{32} & S_{33} & S_{34} \\
S_{41} & S_{42} & S_{43} & S_{44}
\end{array}\right.
$$
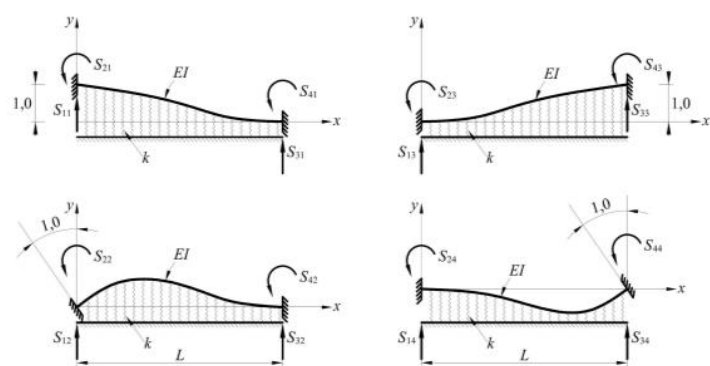

Fig. 2. Beam on one-parameter elastic foundation - terms of stiffness matrix [5]

where the $S_{i j}$ parameter is defined as:

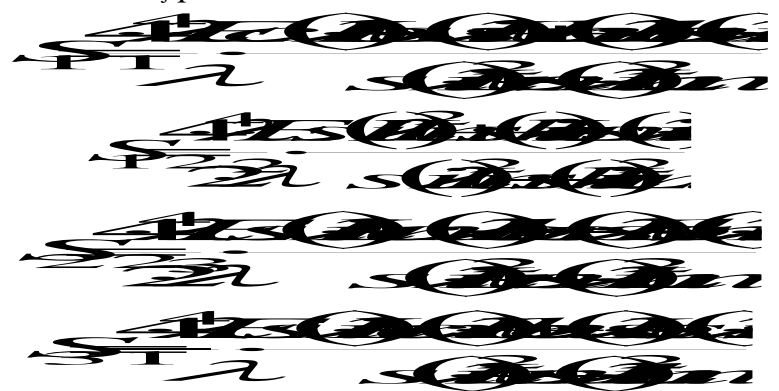




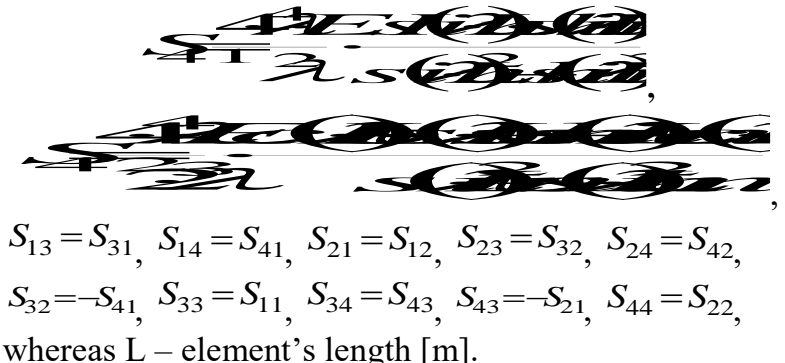

\subsection{A BE beam on a two-parameter Vlasov foundation}

The differential equation for a $\mathrm{BE}$ beam resting on a two-parameter soil has the following form [8,10-13]:

$$
E I \cdot z(x)^{I V}+k_{1}(x) \cdot z(x)-k_{2}(x) \cdot z(x)^{\prime \prime}=q(x)
$$

where $z$-beam deflection; $k_{l}$ - first subsoil parameter $[\mathrm{MPa}] ; k_{2}-$ second subsoil parameter $[\mathrm{MN}] ; q(x)-$ distributed load on beam.

Using Galerkin's Residual Method (GRM) [10] for the two-parameter foundation we obtain:

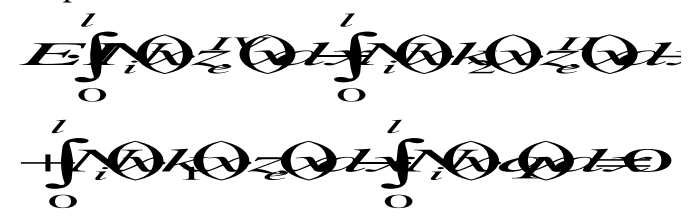

In matrix notation: $\left(\left[k_{E I}\right]+\left[k_{V}\right]+\left[k_{H}\right]\right) \cdot\left\{u_{e}\right\}=\left\{S_{e}\right\}-\left\{R_{e}\right\}$, where: $\left[\mathrm{k}_{\mathrm{e}}\right]$ - beam element's bending stiffness matrix, $\left[\mathrm{kV}_{\mathrm{V}}\right]$ - matrix for the elastic foundation under an the influence of its first parameter, $\left[\mathrm{k}_{\mathrm{H}}\right]$ - matrix for the elastic foundation under an influence of its second parameter, $\left[\mathrm{S}_{\mathrm{e}}\right]-$ vector of reaction to concentrated forces applied to beam (the forces were applied in the beam's nodes), $\left[\mathrm{R}_{\mathrm{e}}\right]$ - vector of reaction to the beam's evenly distributed load.

The solutions of equation (4) are given as matrices $[10,11]$ :

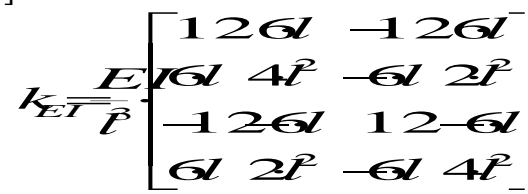

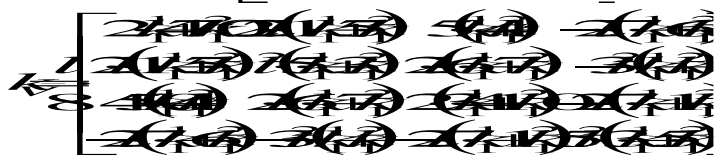

for $k_{1}^{1}=k_{1}^{2}=k_{1}$ :

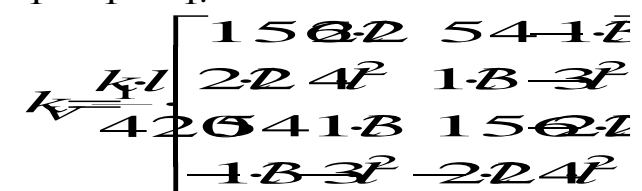

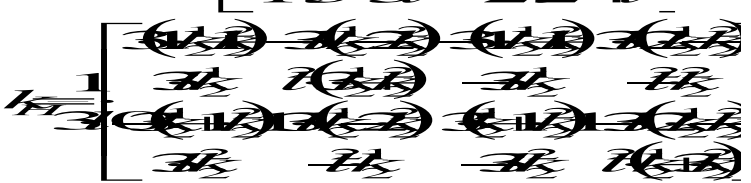

$$
\begin{aligned}
& \text { for } k_{2}^{1}=k_{2}^{2}=k_{2} \text { : }
\end{aligned}
$$




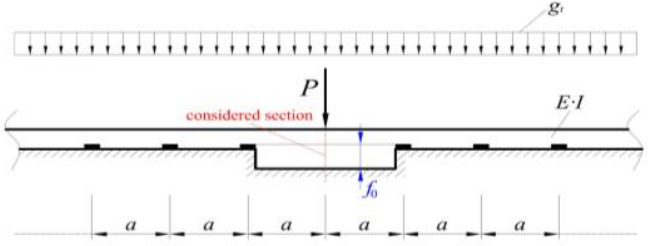

Fig. 3. A local imperfection generated in railway track where f0 - imperfection created in the railway track $[\mathrm{mm}], \mathrm{P}$ - force applied on wheel [MN], EI - railway track stiffness in vertical plane [MNm2], gt - track weight [MN/m], a - railway sleeper spacing $[\mathrm{m}]$.

In the railway track, a local imperfection is generated through track hogging at a defined height (parameter $f_{0}$ on fig. 3). This height irregularity is either caused by loose fasteners or by the use of a railway jack while considering the railway track stability in the horizontal plane according to mandatory regulations). The metal plates are then placed between the rail and the divider. Next, the rail is lowered onto the divider and fastened to the railway sleeper. This method has an intentional imperfection in the track, which is described by its depth $f_{0}$ and its length $2 a$ ). The value of $f_{0}$ is determined at the initial track state $(0[\mathrm{~mm}])$ and the successive states (noted as 1, 2, $3[\mathrm{~mm}]$ ). A total of 12 railway crossings are made by the SM-42 locomotive on the track with the previously created imperfections. The force transferred from the rail to the railway sleeper and the deflections of the railway sleeper were measured and analysed by the PONTOS system. A theoretical analysis of the stated problem is described for one cross-section (considered was a section under an acting $P$ wheel force - fig. 3), in which changes of rail and sleeper displacements are expected to be extreme. These changes are also apparent on fig. 4, showing maximal values under following forces, when a force from a wheel occurs in the very middle of the generated imperfection, the imperfection occurring at a length $2 \mathrm{a}$ from fig. 3. This section was chosen since it allowed to measure particular parameters (such as: a load from the wheel, a deflection or a force transferred from rail to sleeper). In the paper is analysed a static ride (speed below $10[\mathrm{~km} / \mathrm{h}]$ ) of succeeding SM-42 locomotive axles. Considering a small speed of the moving locomotive, the problem is treated as static.

To analyse deflections, an optical measurement system by GOM mbh (Gesellschaft für Optische Messtechnik, Technischen Universität, Braunschweig) was used. The main purpose of this system is to produce 3D digitisation (e.g., in coordinate measurements). The PONTOS system is used for the dynamic analysis of deflections in 3D, making precise (at an accuracy of $0.001[\mathrm{~mm}]$ ), non-contact measurements of position, motion and deformations at short time intervals (on the order of $0.005 \mathrm{~s}$ ). The PONTOS Viewer version v6.3.05 (by GOM mbH) and catmanEasy version 2.1 (by HBM GmbH) programs were used.

The experimental measurements were compared to theoretical calculations, and the experimental results are shown in fig. 4.

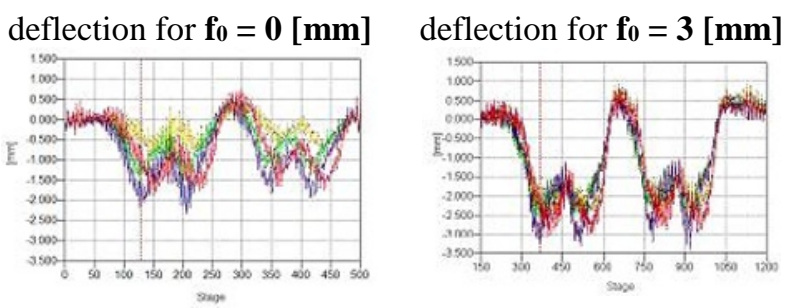

Fig. 4. Measured sleeper's deflection of succeeding SM-42 locomotive axles due to track irregularity (PONTOS viewer)

\subsection{Analysis of theoretical and experimental studies}

Field measurements were compared with the results of theoretical calculations generated for the imperfection scheme shown in fig. 3. Theoretical calculations considered the varying cross-sectional areas of the sleeper. In the cross section, the effect of the imperfection is the most important consideration when analysing the deflection of the railway sleeper.

\subsubsection{Identification of the parameters for theoretical calculations}

For a further analysis presented in this work, exact parameters of the sleeper foundation were determined using results of a test-driving the locomotive without irregularities; the parameters were also determined by methods described in chapter 2 of this work $[1,2,7]$.

In the Vlasov two-parameter foundation model [14], the foundation is treated as an elastic layer, and the constraints are imposed by restricting the deflection within the foundation to an appropriate mode shape described as $\varphi(z)$. The method of determining these parameters is as follows.

The two-parameter Vlasov model accounts for the effect of the neglected shear strain energy in the soil and shear forces that come from the surrounding soil by introducing an arbitrary parameter $\gamma$. This parameter characterises the vertical distribution of the deformation in the foundation [14]. The proper mechanism for the calculation of $\gamma$ is given in publications $[11,12,13]$. The parameter $\gamma$ is determined as a function of the characteristic of the beam (e.g. fig. 1) and foundation soil using an iterative procedure (modified Vlasov foundation). Because the $\gamma$ value needs to be known before the function $\varphi(\mathrm{z})$ can be solved, an iterative approach is used to evaluate $\gamma[12,13]$. The initial value of $\gamma$ is first arbitrarily assumed to evaluate the $k_{1}$ and $k_{2}$ parameters using equations (12) and (13). Next, the value of $\gamma$ is calculated from equation (14) using beam displacements, which is calculated in the previous step. With a corrected value of $\gamma$, the values of $k_{1}$ and $k_{2}$ are again evaluated from equations (12) and (13). The iteration process is continued until the change in $\gamma$ between the two successive iterations is less than the assumed tolerance. 


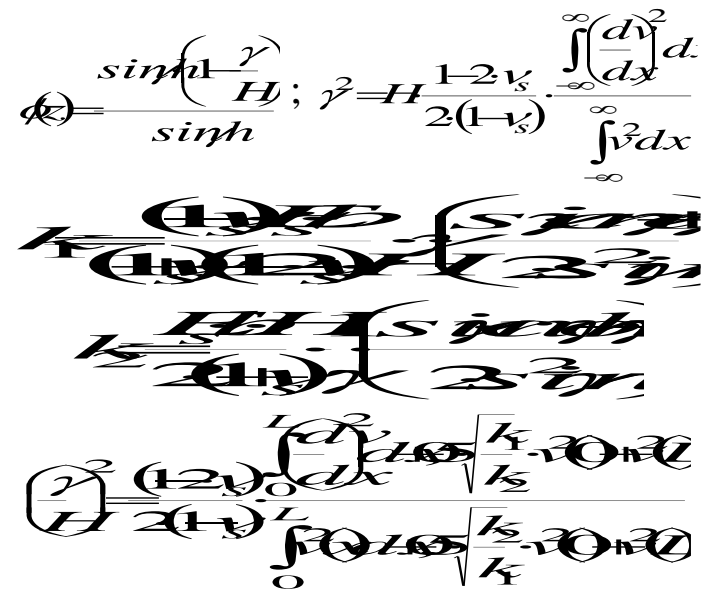

where: $k_{1}$ and $k_{2}$ - foundation parameters; $v_{s}$ - soil's Poisson's ratio; $E_{s}$ - modulus of elasticity (usually measured by a VSS plate); $\gamma$ - arbitrary parameter; $v(z)$ - beam deflection; $H$ - assumed depth of co-operated foundation; $b$ - beam width; $\varphi(\mathrm{z})$ - additional parameter.

A significant change in the vertical stress in the subgrade (representing an impact on the strain) caused by loaded substructure VSS was calculated to have a vertical range from 3.87 to 4.91 plate diameters $D$ [9]. Therefore the assumed depth was $H=1.0[\mathrm{~m}]$.

For $E_{\mathrm{s}}=68,3478[\mathrm{MPa}]$ and $v_{s}=0,2, \gamma=0,57949$ as determined by the iterative process. The values for $k_{1}$ and $\mathrm{k}_{2}$ were $k_{1}=22,8362[\mathrm{MPa}]$ and $k_{2}=2,7262[\mathrm{MN}]$ as determined by equations (12) and (13), respectively. For the analogue Vlasov model [4], on the basis of the field investigations, the flexibility coefficient $k_{u}[\mathrm{MPa}]$ is determined. The coefficient $k_{w}[\mathrm{MPa}]$ is assumed to be identical as the first parameter $\left(k_{1}\right)$ for the Vlasov modified model. The coefficient was used to calculate the railway sleeper deflection derived from the Timoshenko beam of a two-parameter analogue Vlasov ballast ground. The coefficient $k_{u}$ was calculated to be $1,1927 \mathrm{MPa}$ based on [1].

\subsection{Theoretical calculations}

Figs. 5-6 show the railway sleeper deflection and the force transmitted from the rail to the railway sleeper generated from the track's imperfection (c. fig. 3).

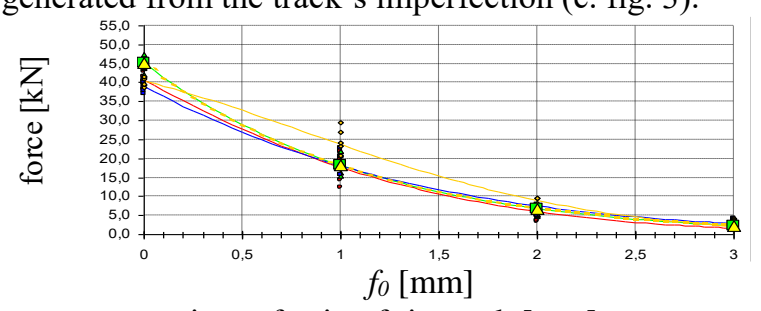

imperfection $\mathrm{f}_{0}$ in track $[\mathrm{mm}]$

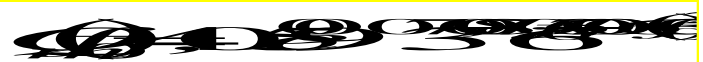

Fig. 5. Value of the force transmitted from the rail onto the railway sleeper of succeeding SM-42 locomotive axles from the imperfection in the railway track (labelled as $\mathrm{z}$ in fig. 3 ) Legend:

$\Delta-$ Values from experimental measurements with locomotive SM42 (Poznań Franowo), $\square$ - Experimental values described with the formula,

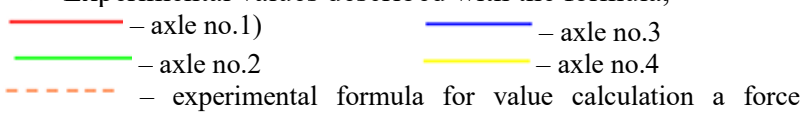
transferred from a rail to a sleeper (dotted line) for axle no.2

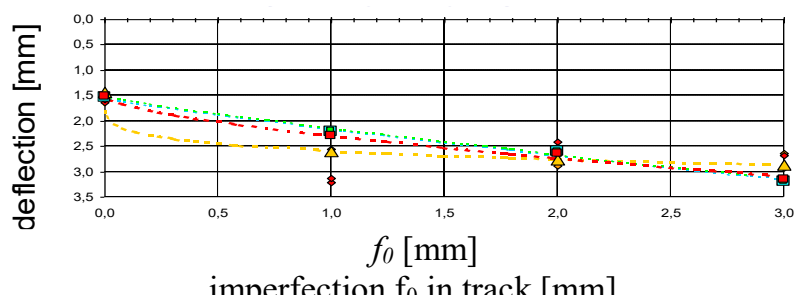

imperfection $\mathrm{f}_{0}$ in track $[\mathrm{mm}]$

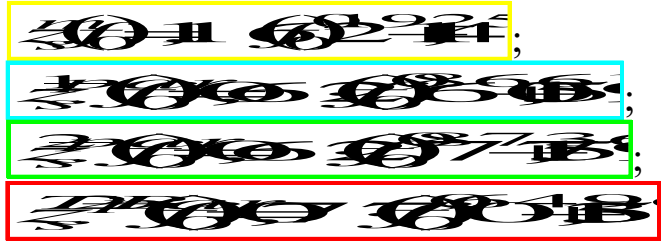

Fig. 6. Theoretical and experimental deflection of the railway sleeper from the imperfection in the rail (as shown in the diagram in fig. 3) in the section in question for chosen axle no. 2 of the locomotive

Legend:

$\diamond, \diamond-$ values from experimental measurements with locomotive SM42 (Poznań Franowo),

$\Delta$ - values calculated with formula describing field research $z_{s}^{m}\left(f_{0}\right)$,

$\square$ - theoretical values MES (1parameter foundation) $z_{s}^{1-p a r}\left(f_{0}\right)$ $\square$ - theoretical values MES (2parameter foundation) $z_{s}^{2-p a r}\left(f_{0}\right)$

$\square_{-}$theoretical values MES (Timoshenko beam on 2parameter foundation) $z_{s}^{T B 2} \operatorname{pa}\left(f_{\mathrm{O}}\right)$

Calculations were performed using finite element matrices using equations and formulas (2-14). The concrete railway sleeper was divided into 80 elements with a length $l=3.125 \mathrm{~cm}$. The following values were applied for a railway sleeper that was treated as a Timoshenko beam:

- the stiffness of the element was calculated as the harmonic mean of the equation;

- $G=\frac{E_{b}}{2 \cdot(1+v)}=0,43 \cdot E_{b}, \quad$ where $\quad v=\frac{1}{6} \quad$ and $E_{b}=35[\mathrm{GPa}]$ (sleeper's Young modulus); $\kappa=1,2$, $\varsigma=\frac{\kappa \cdot E I}{G \cdot A_{e l}}$; where: $G-$ shearing modulus of the element; $A$ - the element's cross-sectional area of sleeper; $\kappa-$ cross-section shape coefficient of the element (assumed value - 1.2); $\varsigma-$ an additional parameter [4]; $\mathrm{S}-$ the compressive force for concrete railway sleeper (assumed $S=0.309[\mathrm{MN}]$ ).

The imperfections of the rail changed the size of the force transmitted from the rail to the railway sleeper. The value of this force is a key parameter for describing the phenomenon of transferring power from the wheel onto the rail and from the rail onto the railway sleeper $(Q)$. Because the force transmitted from the rail onto a sleeper is difficult to estimate, further computational 
analysis will utilise the exact experimental results shown in fig. $5[1,5]$ and table 2.

Table 2. Force transferred from the rail to the railway sleeper due to the $\mathrm{f0}$ imperfection in track - 2nd axle load

\begin{tabular}{|c|c|c|}
\hline $\begin{array}{c}\text { track } \\
\text { imperfection } \\
f_{0}[\mathrm{~mm}]\end{array}$ & $\begin{array}{c}Q_{m}\left(f_{0}\right) \\
{[\mathbf{k N}]}\end{array}$ & $\begin{array}{c}z_{r} \\
{[\mathbf{m m}]}\end{array}$ \\
\hline $\mathbf{0}$ & 45.0936 & 1.9961 \\
\hline $\mathbf{1}$ & 18.2295 & 2.8872 \\
\hline $\mathbf{2}$ & 6.8095 & 3.0541 \\
\hline $\mathbf{3}$ & 2.3504 & 3.5371 \\
\hline
\end{tabular}

Based on the determined value of the force, the force at the end of the deflection of the concrete railway sleeper is then calculated. The concrete railway sleeper was treated as a beam on the one-parameter foundation, on the two-parameter foundation, and as a thickset Timoshenko beam on an elastic foundation, as shown in fig. 6 and Table 3.

Table 3. The railway sleeper deflection $z_{\mathrm{s}}$ due to the $f_{0}$ imperfection in track $-2^{\text {nd }}$ axle load

\begin{tabular}{|c|c|c|c|c|c|c|c|}
\hline \multirow[b]{2}{*}{$\begin{array}{c}\text { track } \\
\text { imperfection } \\
f_{0}[\mathrm{~mm}]\end{array}$} & \multirow[b]{2}{*}{$\begin{array}{c}z_{s} \\
{[\mathrm{~mm}]}\end{array}$} & \multicolumn{2}{|c|}{$\begin{array}{c}\text { one-parameter foundation } \\
\begin{array}{c}k_{1}=22,8362[\mathrm{MPa}] \\
k_{2}=0[\mathrm{MN}]\end{array}\end{array}$} & \multicolumn{2}{|c|}{$\begin{array}{c}\text { two-parameter foundation } \\
\begin{array}{c}k_{1}=22,8362[\mathrm{MPa}] \\
k_{2}=2,7262[\mathrm{MN}]\end{array}\end{array}$} & \multicolumn{2}{|c|}{ 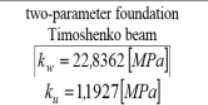 } \\
\hline & & $\begin{array}{l}z_{s}^{1-p a r}\left(f_{0}\right) \\
\quad[\mathrm{mm}] \\
\text { FEM } \\
\mathrm{k}_{2}=0[\mathrm{MN}]\end{array}$ & $\begin{array}{c}z_{k_{1} \neq 0}^{1-p a r} \\
\left(z_{s}^{1-p a r}-f_{0}\right) \\
{[\mathrm{mm}]}\end{array}$ & $\begin{array}{c}z_{s}^{2-p o r}\left(f_{0}\right) \\
{[\mathrm{mm}]} \\
\mathrm{FmM} \\
\mathrm{k}_{2}=2.7262 \\
{[\mathrm{MN}]}\end{array}$ & $\begin{array}{c}z_{k_{1} \neq 0}^{2-p a r} \\
\left(z_{s}^{2-p a r}-f_{0}\right) \\
{[\mathrm{mm}]}\end{array}$ & $\begin{array}{c}{[\mathrm{mm}]} \\
\mathrm{FEM} \\
\mathrm{k}_{\mathrm{u}}=1.1927 \\
{[\mathrm{MPa} \mid} \\
\end{array}$ & $\begin{array}{c}z_{k_{1} \neq 0}^{T B 2-p a r} \\
\left(z_{s}^{T B 2-p a r}-f_{0}\right) \\
{[\mathrm{mm}]}\end{array}$ \\
\hline 0 & & & & 1.5051 & & 1.5162 & \\
\hline & & & & & & 2.2978 & \\
\hline & & & & & & 2.6 & \\
\hline 3 & 2.8731 & 3.1898 & 0.1898 & 3.1857 & 0.1857 & 3.1522 & 0.1522 \\
\hline
\end{tabular}

\section{Conclusions}

Based on the calculations and experimental results, one can state that:

1. A non-destructive method to generate imperfections in the track structure (by placing non-deformable metal plates in the track and force washers in sole-plate) was provided by the author, causing an inviolability of initial contact track/railway sleeper with an elastic foundation. Therefore, this interference from the outside of the railway track allows the imperfections to freely form on a jointless track.

2. The present analysis shows that a structural imperfection in the track can cause a contact loss between the compressed railway track with the local ballast roadbed, leading to a variable force being transferred from the rail to the railway sleeper and finally resulting in the deflection of the railway sleeper. 3. This work successfully resolved the above considerations using a beam element, which simplified the analysis of the obtained results for experimental and theoretical considerations.

4. The analysis was simplified such that the obtained results could be used in computational railway practice.
5. As can be seen on fig. 6 for the obtained theoretical results a best fit of field investigations is for the sleeper treated as Timoshenko beam (TB beam) resting on an analogue Vlasov foundation.

\section{References}

1. Bednarek Wł.: Wpływ pionowych odkształceń nawierzchni i podtorza na prace toru bezstykowego. Seria Rozprawy $\mathrm{Nr} 506$, Wydawnictwo Politechniki Poznańskiej, Poznań 2013,

2. Bednarek Wł.: Determination of foundation coefficients for a 2-parameter model on the basis of railway sleeper deflection. International Conference of Continuous Media with Microstructure II (CMwM II), Łagów, 2015,

3. Chakraborty S, Sarka SK.: Analysis of a curved beam on uncertain elastic foundation. Finite Elem Anal Des 2000;36(1):73-82,

4. Dudzik A, Obara P.: Analiza stateczności belki Timoshenki spoczywajacej na podłożu sprężystym. Architectura, 9 (1), 2010,

5. Eisenberger M, Yankelevsky DZ.: Exact stiffness matrix for beams on elastic foundation. Comput Struct 1985;21(6):1355-9,

6. Eisenberger M, Bielak J.: Finite beams on infinite two-parameter elastic foundations. Comput Struct 1992;42(4):661-4,

7. Kerr AD.: On the vertical modulus in the standard railway track analyses. Rail International 1987;11:37-45,

8. Mullapudi R, Ayoub A.: Nonlinear finite element modeling of beams on two-parameter foundations. Comput Geotech 2010;37:334-42,

9. Pawłowski M.: Zależność wskaźnika zagęszczenia od wskaźnika odkształcenia kruszyw na podstawie próbnych obciążeń płytą statyczną. Rozprawa doktorska, Poznań, 2011,

10. Teodoru I-B, Muşat V.: Beam elements on linear variable two-parameter elastic foundation. Buletinul Institutului Politehnic Din Iaşi 2008;LIV(LVIII):69-78,

11. Teodoru I-B, Muşat V.: The modified Vlasov foundation model: An attractive approach for beams resting on elastic supports. EJGE 2010;15,

12. Vallabhan CVG, Das YC.: Parametric study of beams on elastic foundations. J Eng Mech 1988;114:2072-72,

13. Vallabhan CVG, Das YC.: Modified Vlasov model for beams on elastic foundations. J Geotech Eng 1991;117:956-66,

14. Vlasov VZ, Leont'ev NN.: Beams, plates, and shells on elastic foundation. Jerusalem: Israel Program for Scientific Translations; 1966. (translated from Russian) 